\title{
Traditional Approach towards Contemporary Design: A Case Study
}

\author{
Sushama S. Dhepe, Dr. Sheeba Valsson \\ Associate professor, B.V.D.U College of Architecture, Pune \\ Principal, Shri Datta Meghe College of Architecture, Nagpur
}

\begin{abstract}
Traditional architecture acts as a valuable source of inspiration for contemporary designs. The paper aims to analyse the link established between contemporary architecture that with the traditional architecture; as architecture and time are considered as two variables. The study investigates how traditional architecture has been integrated and manifested in contemporary architecture. The paper examines a contemporary house based on traditional design and a view into the past era. The attempt has been made to explore relevance between traditional architecture and contemporary architecture through a case study. Case study method has been employed to identify various aspects of design for continuity of traditional architecture into contemporary architecture. Case study helped in exploring the traditional architecture of Peshawa period in Pune. It was found that features and characteristics of traditional architecture have been adopted in today's conditions. This study will help in increasing awareness amongst contemporary designers to integrate traditional characteristics, style, elements into contemporary designs. It provides knowledge about how traditional architecture embodied in today's practices.
\end{abstract}

Keywords: Traditional Architecture, Contemporary Architecture, Traditional elements, Traditional styles, Integration

\section{INTRODUCTION}

The literal meaning of 'tradition' is handing down of beliefs, legends, customs, information, from generations to generations. Traditional architecture is much wider term which encompasses vernacular, tribal, indigenous, primitive, popular, anonymous and polite architecture $^{1}$. In its most basic sense, 'tradition' also means something that is transmitted. It is the process of transmission that maintains the tradition ${ }^{2}$.To understand the transmission of traditional architecture in today's context, a case method was undertaken. Case of 'Dhepe Wada' which is located at Giriwan in Pune, built in 2015 was selected for study as its design inspired from traditional Wada typology. Wadas were the residential form of Maratha architecture, evolved under the patronage of Peshwas. Dhepe Wada takes us in the past with regards to the architecture of Peshwa period in Pune. Tradition is always associated with past. For this study; traditional architecture is considered which has been crystallized over a period of time.The study examines how and why design aspects continued from traditional architecture into today's architectures. 'Vishrambaug wada' one of the traditional Wada's in Pune, has been referred for study to explore relation between past and present architecture.

Wada is derived from the Sanskrit word 'Vata' which means plot or piece of land meant for a house ${ }^{3}$. The traditional residence 'Wada' included houses of several families or only one family who stayed there.It is generally used to denote courtyard house mansion. This House form belonged to ruling classes as well as commoners.This typology is very significant in terms of historical, cultural and economic aspects. Though there are certain variations in size, scale and economical status, but all wadas do share some of the basic elements and characteristics. The features of the typical Wada are shown in Figure 1.Contemporary design has been assessed with traditional Wada in this paper. 


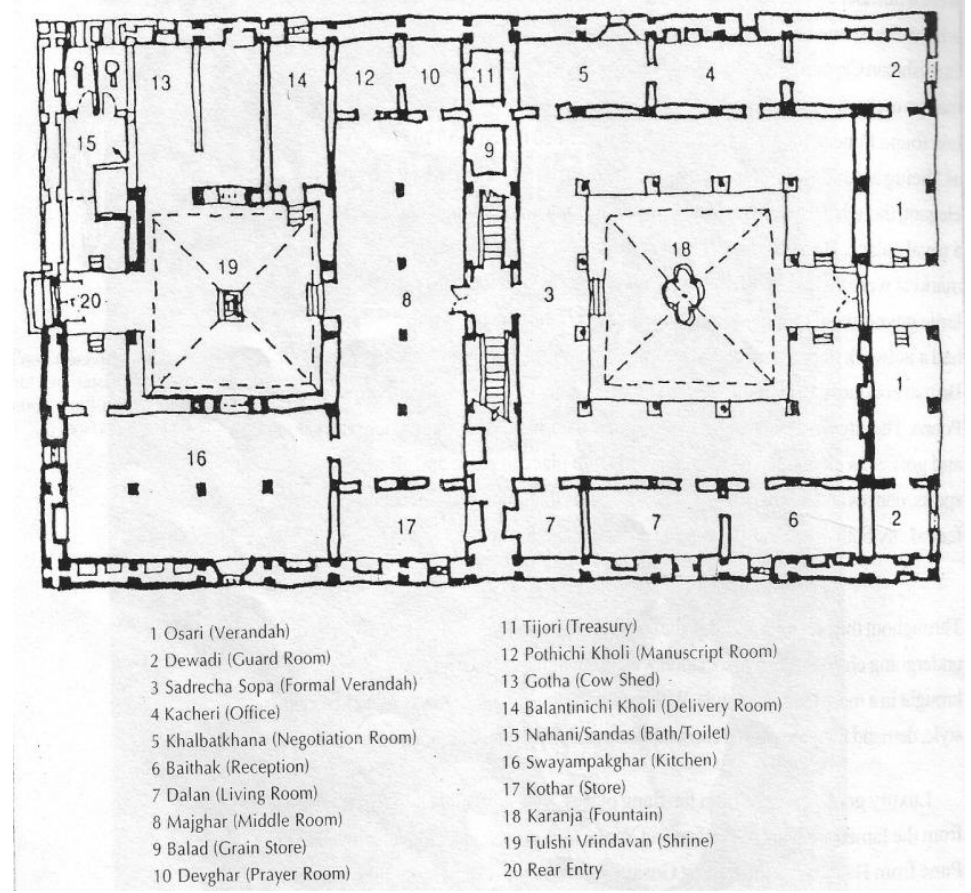

Figure 1 Typical plan of Wada (Source-Diddee J. and Gupta S., 2000, pp.-80)

\section{METHODOLOGY}

A Literature survey was undertaken, to study the features and characteristics of Wada architecture. Case study method has been employed to find out various aspects of design for continuing traditional architecture into contemporary architecture.Dhepe Wada, built in 2015 a case representing confluence of traditional and modern architecture was selected for study. Data was obtained by interviewing the owner Nitin Dhepe. Visit to Dhepe Wada was done in 2015. Dimensions of Wada have been measured and plan was drafted accordingly. Application of traditional features and characteristics in the contemporary design has been evaluated by referring the evidence of traditional architecture as' Vishrambaug Wada', built during final phase of Peshwa by Peshwa Bajirao II. Two cases from different periods that are past and present have been compared in this study. Analysis has been done on the basis of plan form, facade design and various elements to explore traditional architecture embodied in the contemporary architecture.

\section{RESULTS AND DISCUSSION}

Being in real estate Nitin Dhepe had demolished some of Wada's in the past and has constructed flats on in its place. Owner felt guilty while burring the generations and history. Therefore he built a Wada in Girivan, near Mahindra College at Paud, which showcases a glimpse of rich history, culture and tradition of Marathas. Maratha architecture includes Bhosale Period and Peshwas period. Dhepe Wada is designed by architect Awinash Sowani. The architect has done his own study on Maratha Construction technology and inspired from it he used them into today's house form. The Wada has been built with material concrete, common in contemporary; whereas timber was used for structural members in the traditional Wada. Dhepe Wada built on the plot of about two acre, having approximate 8000 sq.ft. built up. The result of continuity in terms plan form, facade design and elements are as follows -

\subsection{Plan form}

Dhepe Wada has been designed around a single courtyard. Courtyard is the focus of planning. It has been surrounded by colonnade veranda with various rooms behind them. Ground floor consists of a outside veranda (osari), pooja room, kitchen and six bedrooms with attached toilet. First floor consists of two halls, six bedrooms and six toilets. Staircase connects the two vertical floors.This Wada follows the grid planning design. Structural grid is of 5' 10 "center to center. The house is oriented towards the east. Spatial configuration in Dhepe Wada is derived from typical Wada plan, that is open space ( angan ) surrounded by semi-open verandah (sopa), and enclosed rooms as shown in Fig,1. This spatial configuration decreases the intensity of light during the transition from outside to inside and useful for spill out activities in semi-open space from open space and built form. Thus, this plan form offers flexibility which was always present in the traditional Wada architecture. 


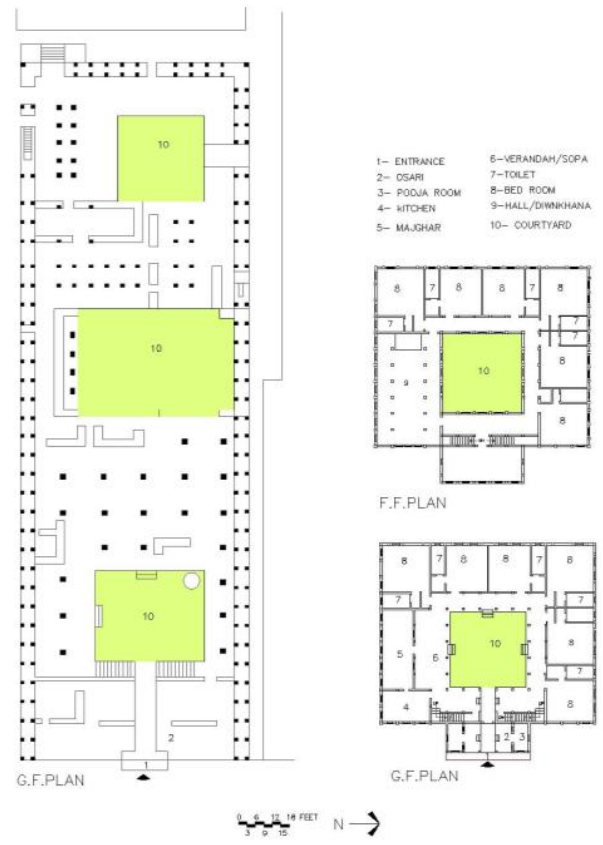

(a) (b)

Figure 2 (a) Plan form of Vishrambaug Wada (Traditional Case) (Source: Gupta R.R. 2013,pp.71) (b)Plan form of Dhepe Wada (Contemporary Case)

The planning and layouts of the Wadas were built around the concepts of a courtyard. The basic planning of all Wadas was introvert and chowk based ${ }^{5}$. Introvert planning provides the sense of enclosure and privacy to the residents of the house.There was a political agenda for adopting introvert planform by Marathas. Being warriors in order to protect their culture and religion against rulers (mainly Mughals), Marathas brought this style of planning. Security and defence were the planning strategy for a Wada. Number of chowks varied from a single chowk upto seven. For more than two courts, outer court used for Public and semi-public purpose and inner court was used for private. Zoning was the important aspect in Wada planning.Courtyard was also important symbolically, as it symbolised inwardness in the house. The centre space is the Brahma space as per vastu shahtra.Visrambaug Wada Figure 2a shows the courtyard patterned layout with three main courtyards one behind the other. The first courtyard is square in plan; the second one which is bigger is rectangular in plan and the third smaller courtyard. Vishrambaug wada is magnificent in size and scale. It shows the grid planning design. Structural grid was called as Khan and the bay formed by number

\subsection{Facade Design}

Exterior façade of Dhepe Wada expresses the traditional style, not the modern style as plain cuboids of concrete facade. Structural grid is clearly visible in elevation of exterior façade of of khan was called Ghaee. Khan was not a fixed unit of length between columns but varied from 5' to 10 '. It is a kind of modular system which offers flexibility and economy for planning process. Considering the privacy, economical, political, functional, cultural and religious aspects Wada plan form becomes significant.

Plan forms of Dhepe Wada indicate similarities in chowk planning, orientation, spatial configuration and spatial grid of traditional Wada.Variations being in size and scale compared to Vishrambaug Wada. Columns used in Dhepe wada are R.C.C columns rather than wooden columns used in traditional Wada. Being concrete columns, space between columns can be increased but to reflect the style of Wada they have been placed closer to each other. Each bed room has attached toilets whereas in traditional Wada toilets located at the rear side of house. The characteristics of Wada's plan form such as introvert plan; structural grid (Khan and Ghaee); spatial organisation providing dialogue between built form and open space have been retained in Dhepe Wada. Whereas features such as symmetry; square or rectangular geometry of Wada planning have been continued in Dhepe Wada.

Wada similar to old testimony, Vishrambaug wada. An element of decoration such as cusped arch which is non-structural false arch within each bay has been borrowed from Peshwas traditional architecture. Style of Peshwas architecture was an 
amalgamation of various other styles like Rajasthani, Gujrati and Delhi. Style of window design; manner of placing covered platforms and guard rooms (devadis) at each side of entrance door indicates similarities of façade design. Smaller openings above the wooden tall windows relate to both the Wadas.

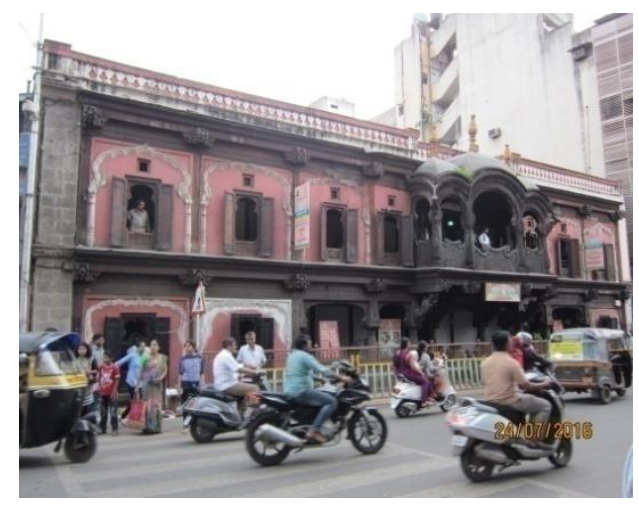

(a)

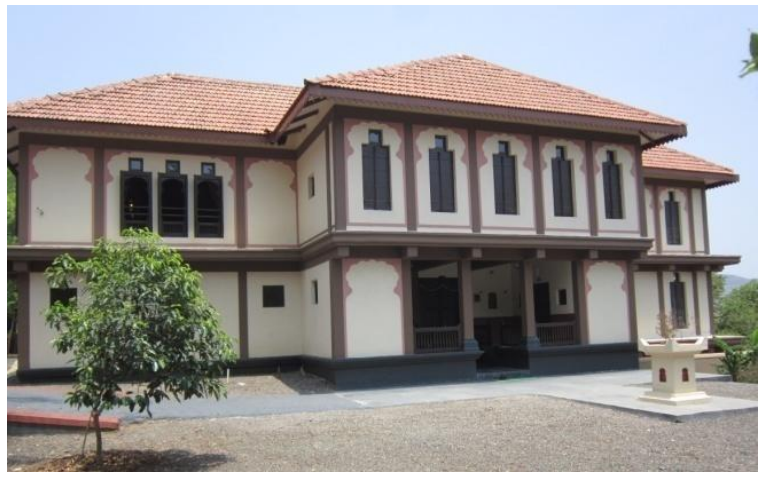

(b)

Figure 3(a) Eastern Façade of Vishrambaug Wada (Traditional Case)

(b) Eastern Facade of Dhepe Wada (Contemporary Case)

Visrambaug wada's facade has a classic wooden balcony called meghadambari (a cloud capped balcony ) projecting from it. Facade is very ornamented belonging to ruling class. Whereas, facade design of Dhepe Wada is simple in terms of carving, articulation of structural members.Dhepe Wada's facade does not have a balcony but there is an entrance projected out in plan.

\subsection{Elements}

There are various elements in architecture such as spatial element, construction elements, and structural elements. There are some elements related to decoration also. But certain thematic space and its elements are significant in traditional architecture considering cultural, climatic and functional implications ${ }^{8}$. Attempt has been made to understand transition and continuity of elements.

\subsubsection{Thresholds}

The idea of threshold always had a special significance in traditional architecture of India and Pune is not an exception. It signifies the transition of space from public to private ${ }^{6}$. It connects inside and outside; external and internal; open and enclosed. This spatial element has been associated with metaphysical ideas because of which two opposite worlds come together. Wada often has platforms at the entrance from the street. It was locally called as 'osari'. A verandah like space which has two platforms on each side of door, with pillars supporting the upper floor. 


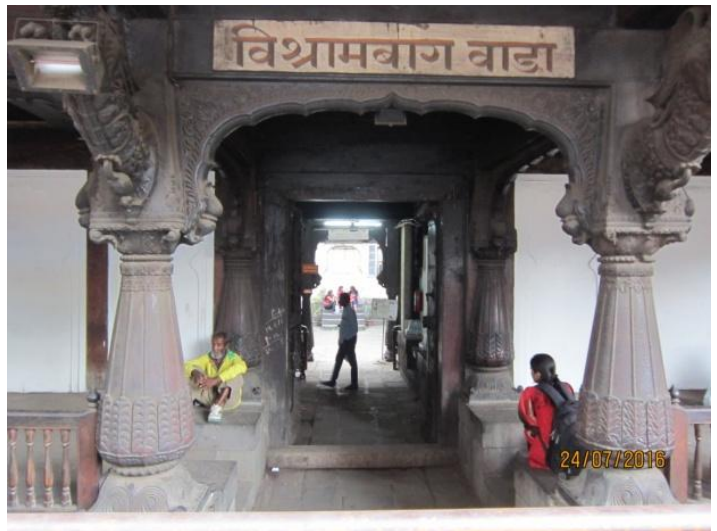

(a)

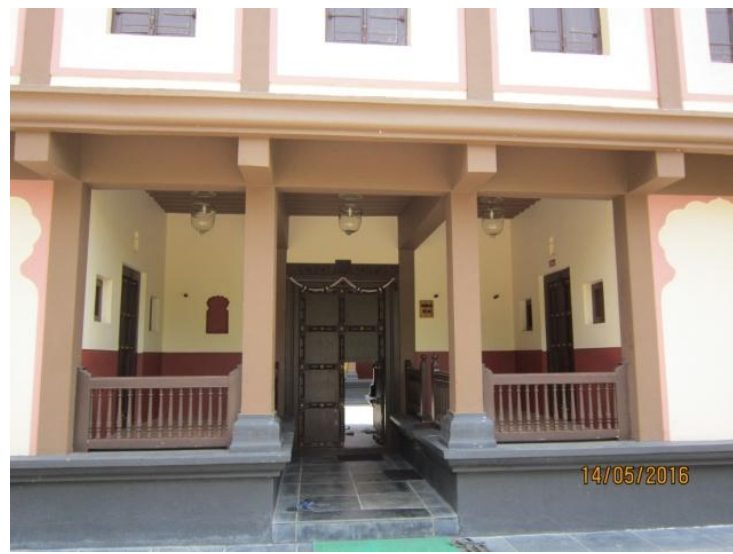

(b)

Figure 4 (a) Entrance of Vishrambaug Wada (Traditional Case)

(b) Entrance of Dhepe Wada (Contemporary Case)

This transitional space encourages residents and passers-by to pause for conversation and helps the residents of the Wada to get connected with the neighborhood socially. It provides an interactive space. In Wada platforms of threshold are slightly elevated so that they act as the mode of transition between built form and land. It provides shelter from sun and rain. This element has paramount importance which provides social, cultural, functional, climatic and religious implications.Similarly, the entrance to the Dhepe Wada has two platforms though the size, articulation and material of components of osari have been changed. In Vishrambaug Wada the entrance is constructed within seven bays, between two devadis which was used as a guard room whereas the entrance at Dhepe Wada consist of three bays and devadi replaced a pooja room forming the platforms. Columns are very decorative circular in shape and supported to balcony in Vishrambaug Wada.The cusped arch non structural member can also be seen at the entrance. The wooden brackets are supported by four ornate winged yalis or a combination of lion, eagle and crocodile considered as good omen. The R.C.C. columns of Dhepe Wada are simple at entrance. Ornamented brackets are not used but plinth with stone is similar to old architecture that is used as a testimony.

\subsubsection{Courtyards}

Wada cannot be imagined without a courtyard in Maharashtra. It was a core element in design of wadas. Vishrambaug Wada has three large chowks. The first and second courtyard was used for administration purpose.The personal rooms were in last courtyards i.e third courtyard Figure 6 a. It was used for personal use by Peshwa Bajirao II. The last courtyard has fountains and middle courtyard has two wells which cools the interior of the Wada even during scorching summers. The middle courtyard is bigger than the last and front courtyard. 


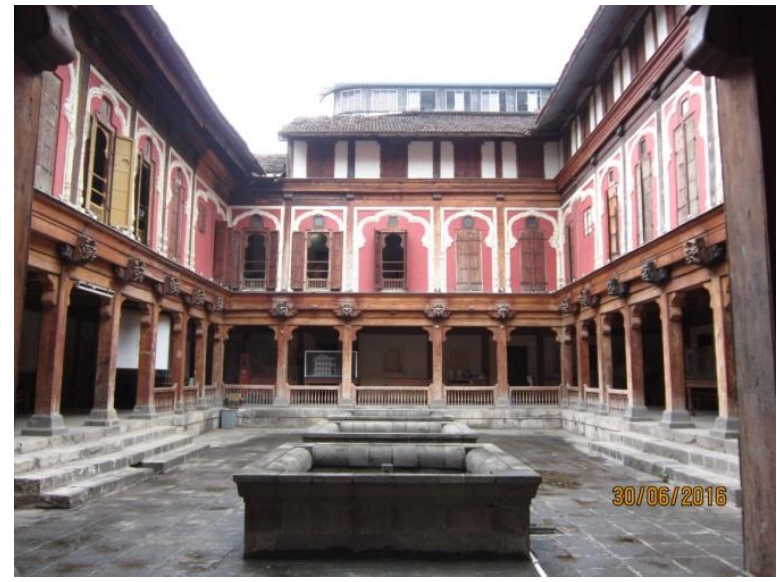

(a)

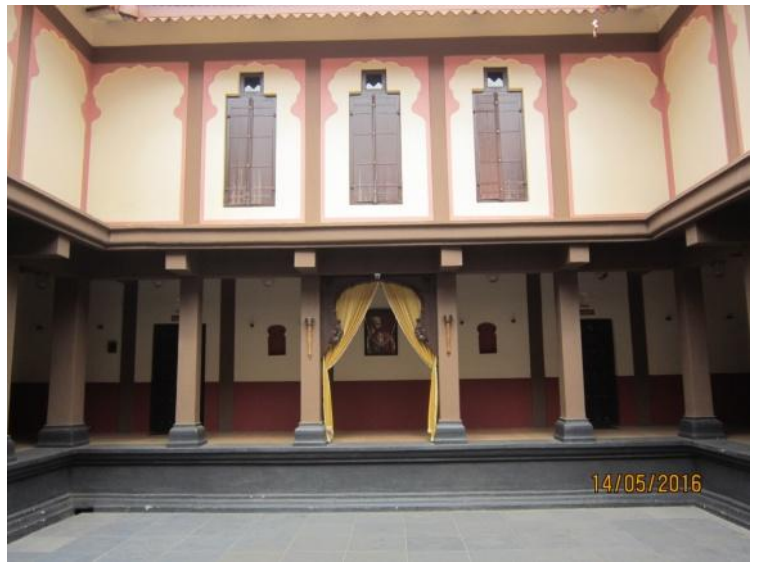

(b)

Figure 5 (a) Courtyard (Third Court) in Vishrambaug Wada (Traditional Case) (b)Courtyard in Dhepe Wada (Contemporary Case)

Dhepe Wada has the single courtyard Wada. The Court is utilised for various functions as in old days. Court has open verandas with pillars around and behind them there are the enclosed rooms on the ground floors and the upper floor is enclosed with walls. Spatial configuration is same as Vishrambaug Wada but wood has been used as the material of column and beam has been replaced by RCC material. All the first floors have ornamental wooden windows facing the courtyard. The flooring of the chowk and the surrounding plinth are usually made of stone. Vishrambaug Wada is an exemption but it is clearly visible in Dhepe Wada. The Vishrambaug Wada is covered with timber roof on all wings. It has tiles over the wood finish. In Dhepe Wada timber roof has been replaced with galvanised iron sheets. These sheets are covered again with tiles showcasing typical feature of Peshwai architecture. On the interior facades of chowks in Vishrambaug Wada ornamental patterns are raised in the plaster in each bay. They are like floral garlands in the shape of the cusped arches as used in the window. Similar expression is visible in Dhepe Wada.The brackets facing the courtyard in Vishrambaug Wada have been beautifully carved with wooden decorative mounts with parrots, flowers, peacocks, banana leaves and many other decorative motifs where as brackets in Dhepe Wada are very simple without any ornamentation.

The characteristics of a courtyard as an element in traditional architecture are that it connects inside and outside space. This space connects ground floor and upper floors and family or families living around the space. It is private outdoor space that becomes public space for gathering at the time of festivals and cultural programmes. It provides an interactive space. Every room designed is facing towards the courtyard. This open space is used for various activities such as gathering, gossiping, resting, cooking, washing, performing rituals, dining, playing etc. This flexibility to interior space also provides economic aspects. It is an environmental space that offers Light and ventilation, landscaping, cooling, wind gathering etc. These characteristics of courtyard as spatial elements with style are enduring in the Dhepe Wada. 


\subsubsection{Verandahs}

In Wada, the court was surrounded by a semi-open passageway with columns known as sopa.It was extended inside verandah. Sopa served as an un-programmed space in which activities held in enclosed rooms as well as in open court were spill out. Activities from Kitchen, storage were extended in the Verandah.It used for dining called as 'Pangaticha Sopa ${ }^{3}$.This space was also used for entertainment purpose. Usually swing was the recreational element and feature of the verandah ${ }^{7}$.
Verandah diffuses light and provides shelter from Sun and rain. It is a transitional element of space. It became significant providing various aspects such as cultural, climatic, functional, religious. Dhepe wada has four sopa around a Courtyard on the ground floor alike Vishrambaug Wada but wooden columns have been replaced by R.C.C. Columns. Style of column base design and ceiling design are analogous as in Peshwai architecture. The sopa is without railing placed. The swing is used as an integral part of the sopa in front of Majghar.

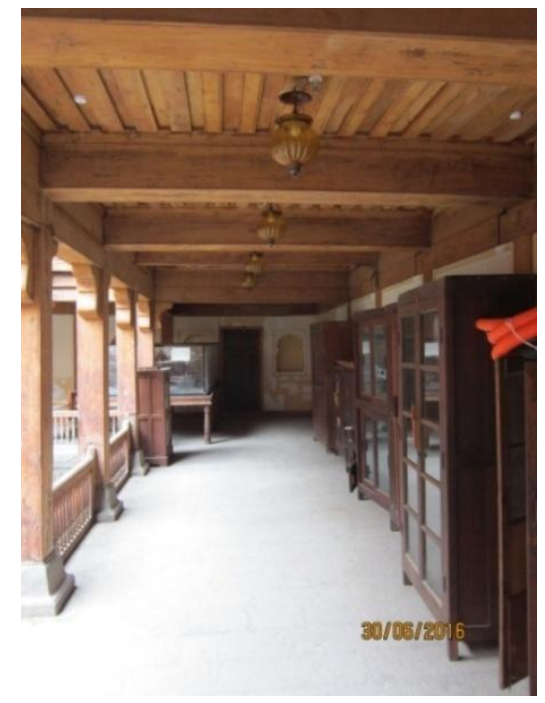

(a)

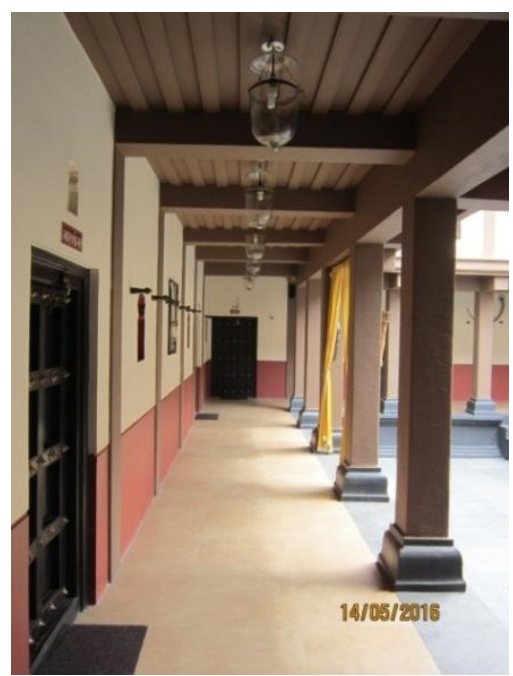

(b)

Figure 6 (a) Verandah in Vishrambaug Wada (Traditional Case )

(b) Verandah in Dhepe Wada (Contemporary Case)

\subsubsection{Doors}

In old Wadas, the dominating feature of the external facade was the large entrance doorway made of wood. This main entrance doorway had a smaller doorway within called the Dindi Darwaza.Only the small doorway, dindi, kept open for regular use. This was obviously for security reasons and making enter someone's domain in a very humble manner. The doorway also had a carved strip at lintel level with auspicious symbols known as the Ganesh patti.The fixtures were of iron. 
Vishrambaug Wada shows the main door with large size, having dindi and iron fixtures. Main door of Dhepe Wada has been in accordance with size, material and aesthetic of the older structure. Style of dindi Darwaza retained to recall the feel of old Wada and symbolism characteristic has continued by placing Ganesh patti at apex of entrance in Dhepe wada. Door as a stylistic element with characteristic has been picked in Dhepe Wada.

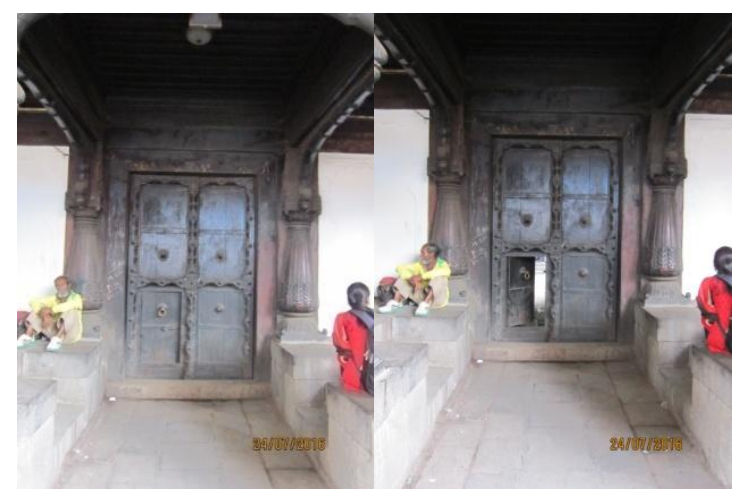

(a)

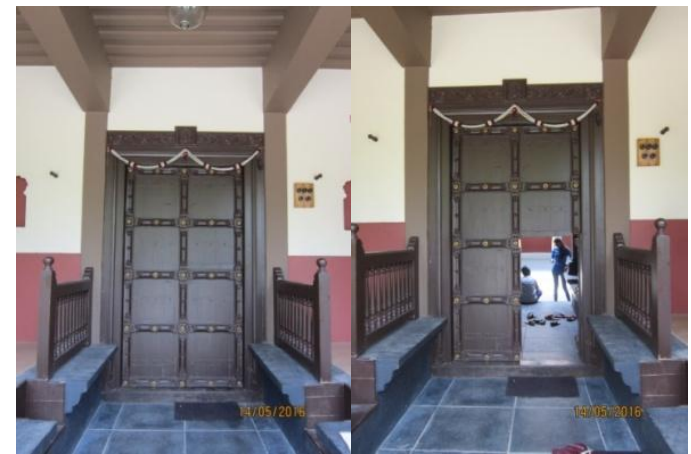

(b)

Figure 7 (a) Entrance Door in Vishrambaug Wada (Traditional Case )

(b) Entrance Door in Dhepe Wada (Contemporary Case)

\subsubsection{Windows}

Full height wooden windows, having cupsed arch, extended from floor to height with smaller square opening on top with two shutters has been seen in Dhepe wada in order to convey the picture of Peshwai period. In old Wadas usually, windows were narrow but tall and upended from floor level. Such window design provides view when one was sitting with folded leg and even one was standing on the floor.It also provides flow of wind at floor level.Windows were having wooden railing for the protection and with the typical Peshwai arch (cusped arch )for ornamentation. Wooden bars were placed across the width at one or two places. All the windows were made of wood. Vishrambaug Wada shows the full height windows with one of the Peshwai feature of using smaller square window on top with glass panel. This small opening could be because of the limited size of the glass panes that had to be imported from Britain or the Europe ${ }^{5}$.

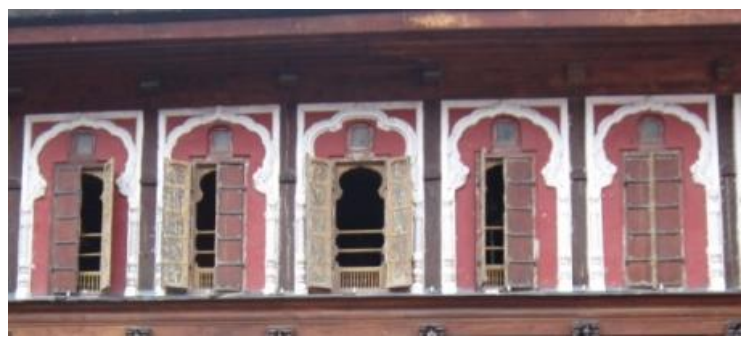

(a) 


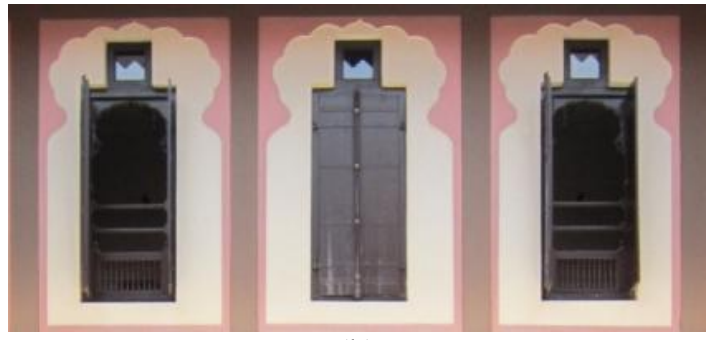

(b)

Figure 8 (a) Windows in Vishrambaug Wada(Traditional Case )

(b) Windows in Dhepe Wada (Contemporary Case)

\subsubsection{Staircase}

In old Wadas, staircase usually dark and sandwiched between the two walls ${ }^{3}$. This may be one of the way of maintaining privacy so that women wouldn't be seen from the outside when moved around in the house ${ }^{5}$.In Vishrambaug Wada thick brick walls accommodates staircase whereas in Dhepe Wada staircase is contained by the brick wall with 9" thick. Staircase updated with light in contemporary design. The style of staircase has been persistent in Dhepe Wada.

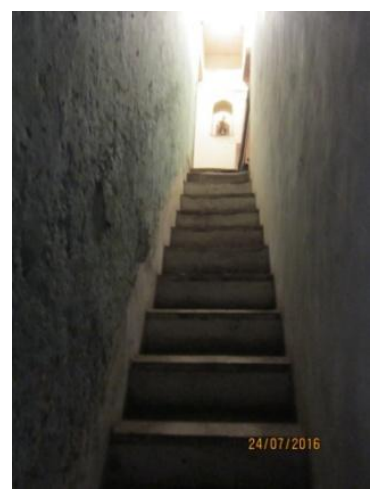

(a)

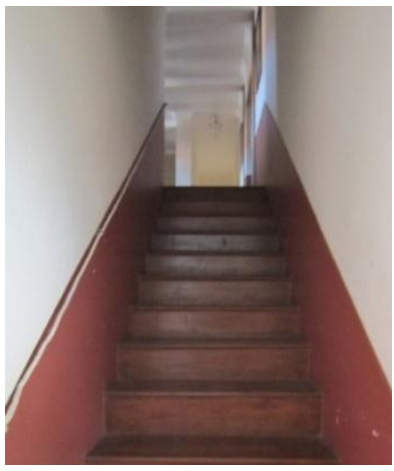

(b)

Figure 9 (a) One of the staircase in Vishrambaug Wada (Traditional Case ) (b) Staircase in Dhepe Wada (Contemporary Case)

\section{4 Halls}

Every wada had one or much more halls for entertaining guests and private functions. It was called as Diwankhana. Free standing wooden columns were a feature of all the diwankhanas. Columns were usually of cypress shape and supported on stone base. The wooden cusped arches or Miharab were placed between these rows of columns.The ceiling had intricate carving. Ceilings were usually of wooden planks which were then covered with intricate floral and geometric lace like patterns. Chandeliers and hanging lamps were provided in the ceilings. ${ }^{5}$ Diwankhanas in Vishrambaug Wada (Figure 10a) stand testimony to more gracious time of Peshwas. On the two sides of the main central hall were the smaller passage ways with full height windows overlooking the court or both the sides with smaller square opening on top. 


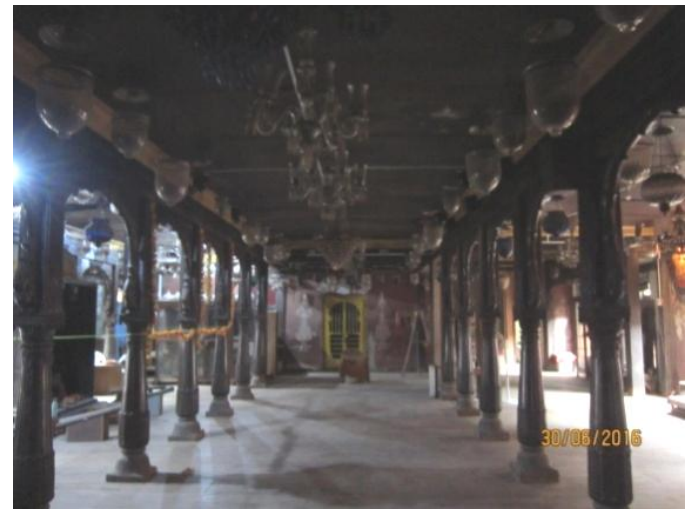

(a)

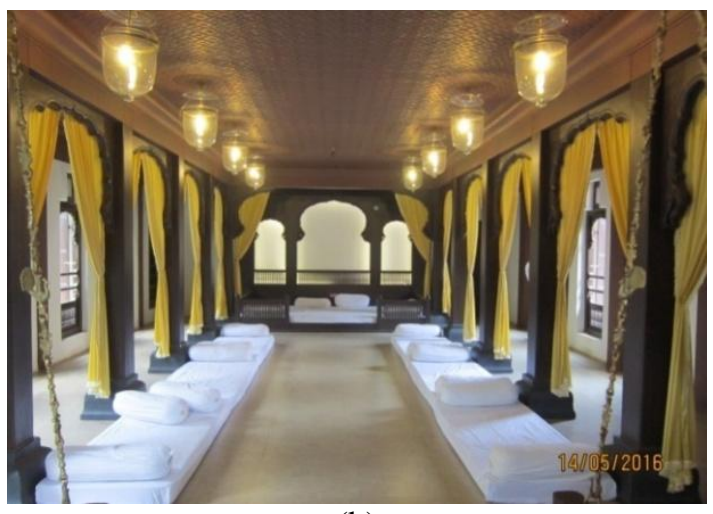

(b)

Figure 10 (a) Hall (Diwankhana) in Vishrambaug Wada (Traditional Case )

(b) Hall (Diwankhana) in Dhepe Wada (Contemporary Case)

Hall interior of Dhepe Wada is like traditional Wada.The hall of the Dhepe Wada is embellished with columns, cupsed arches, ornate ceilings and hanging lamps very typical of every Maratha and peshwai edifice. But columns in

\section{INFERENCES}

Dhepe Wada has retained features and characteristics of traditional architecture in design. Plan to plan; room to room; facade to facade (interior and exterior); courtyard to courtyard, verandah to verandah (inside and outside ); staircase to staircase and openings to openings (Door and windows) have been depicted the continuity of traditional architecture in Dhepe Wada. The table below shows continuities and changes irrespective of materials in design. Similarities indicate in retaining courtyard planning concept, spatial grid,
Dhepe Wada are square shafted columns rather than cypress shaped. Traditional style seating that is low level seating is placed in the hall and a swing has also been provided as traditional important element for audio notes.

spatial and constructional elements, style, pattern and aesthetic, scale and proportions etc. But the materials of structural elements have been changed. Using wood is not sustainable in today's context for structural members such as columns; beams and slab are replaced by RCC. Wood as a material is continued for doors and windows to fetch the clear image of the old house. Each bed room is designed with attach toilets with respect to today's lifestyle and false ceiling has been added for interior of enclosed rooms on the first floor.

Table 1 Continuity and Change of traditional architecture into contemporary architecture

\begin{tabular}{|l|l|l|l|}
\hline \multicolumn{2}{|l|}{ Aspects } & TRADITIONAL WADA & CONTEMPORARY WADA \\
\hline \multirow{2}{*}{ Plan } & Character of plan & Introvert & Introvert \\
\cline { 2 - 4 } & Geometry of plan form & Rectangular & Square \\
\hline
\end{tabular}




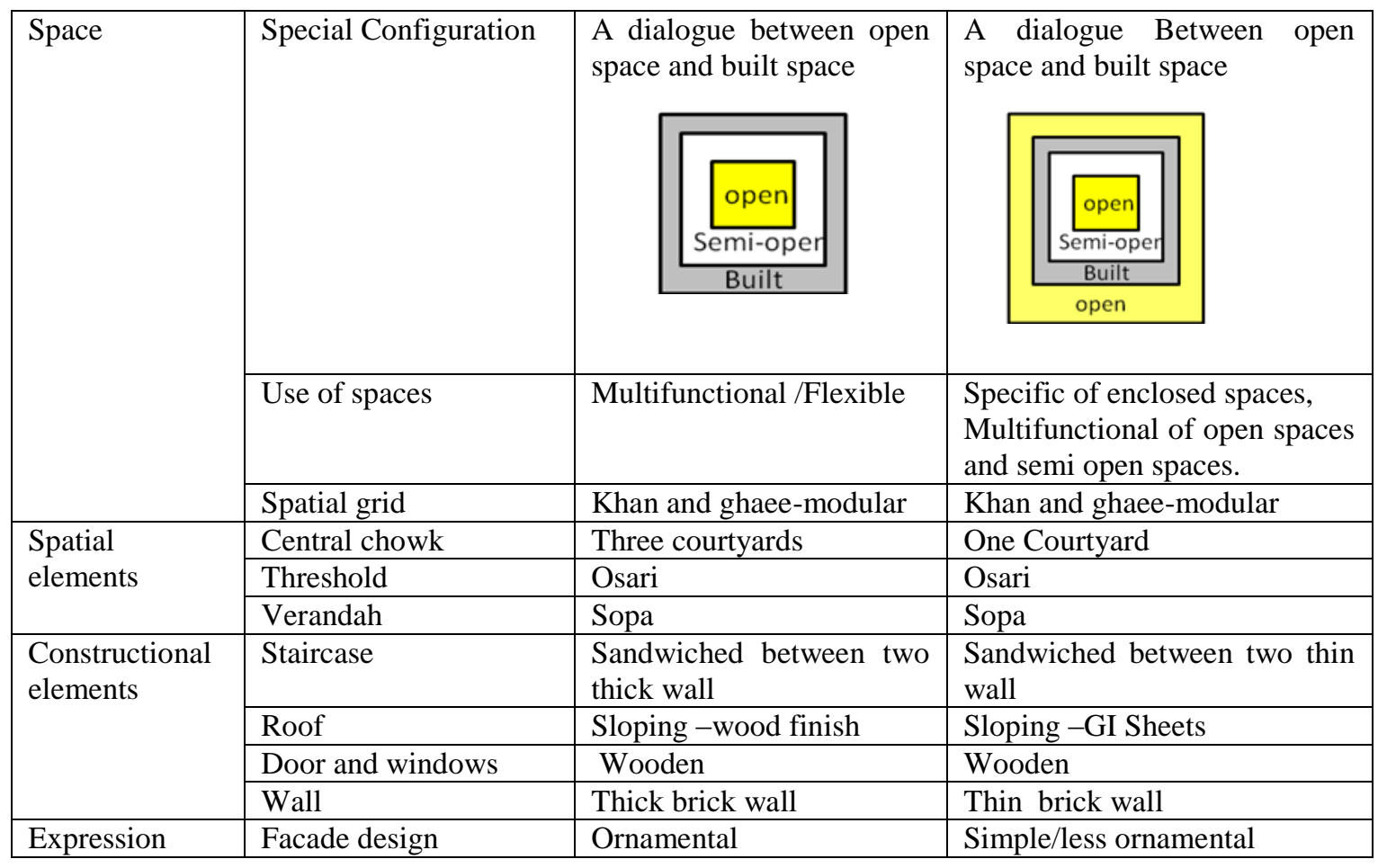

\section{CONCLUSIONS}

The present case has illustrated that it's normal to imply traditions nowadays irrespective of material. Use of traditions and traditional methods has manifested in contemporary architecture by several ways such as using elements, characteristics, style, and expression. Continuity of traditional architecture nowadays, has been

\section{REFERENCES}

[1]. Bourdier J. P. \& Alsyyad N., Dwellings Settlements and tradition: cross cultural perspectives, University press of America, New York, London. 1989,5.

[2]. Alsyyad N. \& Elena Tomilson, Traditional Environments in Post-traditional world: interdisciplinary perspectives (http://www.eolss.net)

[3]. Gupta R. R., The courtyard Wada of Maharashtra, Council of architecture New Delhi,India. 2013,pp.-39-62.

[4]. Diddee J. \& Gupta S., Pune Queen of the Deccan, Elephant Design Pvt.Ltd. PuneIndia.2000,80

[5]. Kanhere G. K., Temples, Wadas and Institutions of Pune: A legacy and Symbolism in architecture,BNCA ,Pune. 2013, 121-123.

[6]. Thapar B., Manto S. K.,\& Bhalla S., Introduction to Indian Architecture, periplus edition (HK) ltd.2004,20. considered by the style as well as borrowing elements. An element includes spatial elements such as courtyard, verandas, threshold at entrance and visual elements consists door, windows, ceilings, columns, roofs etc. Stylistically integration made visual image of Peshawa Architecture through expressions of facade design and elements.

[7]. Dengle N., The Introvert and Extrovert Aspects of the Marathi House, House and Home in Maharashtra, USA, Oxford University Press. 1998, 50-69.

[8]. Jain K., Thematic Space in Indian Architecture, India research press, New Delhi, India.2002, 1-16. 